\title{
Método interdisciplinario \\ de enseñanza
}

La noción de método interdisciplinario puede prestar, a primera vista, a cierta confusión. ¿Cómo entender la palabra "interdisciplinario" en su verdadero sentido primordial? ¿Se trata absolutamente de una novedad que se distinga más o menos radicalmente del método disciplinario llevado a cabo dentro de una asignatura tradicional bien definida, universitaria o escolar?

Para dar razón al método interdisciplinario, al menos desde mi perspectiva o, mejor dicho, perspectivas, es necesario subrayar que la introducción del nuevo método que aspire a tener una importancia general, no se niega a reconocer toda la riqueza de conocimientos adquiridos durante la enseñanza de literatura en grados secundarios o superiores. Por eso debería hablarse más bien de una profundización o ampliación del método común que considera por separado variedad temática de cada disciplina teórica e histórica impartida hasta ahora en el campo de la literatura nacional.

Es cierto que la explicación de los fenómenos que constituyen el conjunto relativamente cerrado de una literatura nacional adquiere nuevas dimensiones a condición de una ampliación de sus horizontes hacia el espacio supranacional. En ese sentido la noción de interdisciplinario tiene como objetivo un intento por franquear los límites de una sola literatura. Sin embargo, esa actividad pedagógica y epistemológica no debería ser de modo alguno complicada e irrealizable. Al contrario, exige una misma preparación teórica e histórica, pero al considerar más el sentido práctico de enseñanza.

Es obvio que ni siquiera en los tiempos de globalización europea que permite ensanchar nuestros conocimientos, no se llega a excluir definitivamente toda la herencia histórica delimitada hasta ahora por una existencia perdurable de las literaturas nacionales. La única diferencia consiste en que las literaturas dejan de representar una realidad autónoma por lo cual se abarca, con más atención y legitimidad, el diálogo literario y cultural existiendo desde siempre entre ellas. Y es la traducción literaria que es la expresión más adecuada de ese diálogo.

La cuestión esencial es saber cómo transcurre dicho diálogo, cuál es su aporte desde un punto de vista dinámico y procesal ¿Qué lugar tienen las obras 
traducidas en la recepción de nuestro lector? ¿Qué problemas plantea, por ejemplo, una desigualdad evolutiva de diferentes literaturas? ¿Hasta qué punto es posible transponer lo más íntegramente una obra extranjera a otras condiciones históricas sin que ésa pierda su misión primordial? ¿Cuándo sucede la situación en que tal o tal libro sea un aporte valioso en función de deseada innovación? ¿En qué reside la traducibilidad o intraducibilidad de un texto original? ¿Qué recursos consiguen vencer una serie variada de obstáculos lingüísticos y propiamente literarios? No he mencionado que algunas cuestiones con las que tiene que enfrentarse no solamente un traductor profesional sino también el estudiante de un idioma extranjero que desea ser efectivamente un buen traductor.

Se sabe que el nacimiento de la disciplina nueva, llamada a mi modo de ver y un poco erróneamente traductología, nos permite responder a esas cuestiones. $Y$ conocer que en cada acto de traducir surgen imprevisiblemente otros factores que se deben atender, sea semánticos sea léxicos o estilísticos.

$\mathrm{Al}$ inicio he destacado el papel enriquecedor de la enseñanza interdisciplinaria. Su común denominador es el trabajo permanente con la traducción que se realiza en cada uno de los cursos o seminarios impartidos. Son la Historia de Literatura, la Teoría Literaria, la Estilística y la Traducción Artística. Es importante señalar que el conjunto de las cuatro asignaturas contribuye al mejor aprendizaje del idioma extranjero. Ya que para "saber literatura", no basta conocer sólo la historia literaria. Se necesitan asimismo conocimientos de gramática, de teoría literaria con todo el inventario de reglas y normas así como la terminología relativa a cada una de esas disciplinas. La ventaja de dicho método combinatorio es clara: se aplica tanto por separado, dentro de dadas asignaturas, como en extensión, durante la traducción misma de un texto literario. Su selección depende del escritor que se estudia momentáneamente en las clases de historia literaria.

La primera fase de enseñanza transcurre valiéndose de manuales de historia literaria para "encuadrar" bien la obra que se lee y, después, se traduce al eslovaco. El autor está localizado según sus coordinadas geográficas, sociales e históricas, junto con los datos biográficos. Para la traducción misma se elige un fragmento de su obra, habitualmente muy breve pero representativo, resumiendo lo mejor posible los rasgos de su poética. En esa fase es importante observar en primer lugar el contexto de la literatura extranjera. La historia literaria nos sirve de instrumento básico para la explicación de un texto literario y el comentario acerca de sus cualidades, lingüísticas, poetológicas y estéticas. No olvidemos que el texto no debe ser muy difícil, pues tiene que corresponder 
a los conocimientos del idioma extranjero según el grado de enseñanza. Sólo gradualmente se puede proceder a la elección de textos más complicados, con utilización de varios aspectos comparativos que se están perfilando en relación con la literatura y el idioma eslovaco.

En resumen, la enseñanza consta de dos partes que funcionan por separado y por su unión al aprovechar primero el contenido mismo de la historia literaria. Mientras que la segunda se apoya también en lo que no se puede aprender directamente, sino por disposiciones individuales de los estudiantes, por su capacidad de creación y recreación del texto original. Se comprende, esa actividad obliga a transcender los límites del aprendizaje positivo de un idioma extranjero: se libera poco a poco del método racional para pasar al estadio de una participación activa de intuición e imaginación. Está claro que el pasaje de lo racional a lo empírico o lo intuitivo es inevitable en función de la equivalencia estética que es necesaria en cada traducción.

No obstante, si se medita en los fines de la enseñanza, aquella meta parece todavía muy lejana en primer contacto con el original. Es que la traducción supone un orden de explicación que se desarrolla desde lo simple a lo más complicado. Tiene que fundarse en la fase preparatoria o propedéutica. Desgraciadamente, esa fase está abandonada muchas veces en los últimos años, ante todo con respecto al sentido práctico de enseñanza.

Llegamos pues a otra rama de conocimientos que forma parte de ese proceso. Reside en el ámbito de Teoría Literaria. Digámonos que los resultados modernos de la teoría literaria son tan relevantes que nos acercan más al problema esencial de una equivalencia semántica considerada, en general, como el objetivo primordial de la traducción. Tanto más que uno de sus aportes significativos, que es la Teoría de la Comunicación, pone de relieve la necesidad de un sistema que por su rigor sea válido para todos los idiomas. Es cierto que con la teoría literaria nos situamos ante la cuestión clave de la creación artística. Gracias a Aristóteles y su obra Poética nos damos cuenta de que la actividad artística es el resultado "consciente" de cierta habilidad, de una técnica orientada a la creación estética. En la luz de la Poética una obra deja de representar una inspiración incontrolable y se hace un esfuerzo reflexivo por captar las leyes internas de composición artística.

A diferencia de Platón, el célebre maestro de Aristóteles, se subraya la forma misma de expresión, el aspecto lingüístico del texto literario. Ése comprende un código especial que se aleja de ordinario de la lengua habitual dando origen a valores connotativos. De tal manera vemos en una obra artística la dualidad sistemática que funciona en cada idioma. Sin duda, el conocimiento del 
mecanismo interno de creación nos ayuda a penetrar en la estructura misma del original cuyas partes constituyen un todo solidario. La función específica del texto literario es la de procurar un placer estético. Con valor connotativo se puede observar que la expresión artística rompe los límites de su habitual significación y adquiere amplias posibilidades de analogías y de inesperada sugestión. El lenguaje literario se manifiesta siempre a través de las oposiciones verbales que aseguran su función estética.

Ahora bien, la teoría de la comunicación literaria contiene el concepto que se orienta a la composición misma de una obra artística, a sus rasgos constructivos. Insiste en los factores objetivos mediante creación de un sistema binario al afirmar que cada uno de los componentes está en íntima relación con los demás. No es inútil preguntarse hasta qué punto sus instrucciones o procedimientos sean válidos para la traducción misma. Puesto que ésta considera no solo un hecho lingüístico sino también expresión subjetiva del autor, su visión original de la realidad o su lugar histórico en la literatura nacional. Sin embargo, el gran aporte de esa teoría consiste en que llama la atención a varios aspectos lingüísticos y formales bajo una visión global, general. Supone sobre todo que el descubrimiento de las relaciones y correlaciones que existen en la estructura de una obra, conduce a la mejor comprensión de propiedades constitutivas de los idiomas, propiedades gramaticales, morfológicas y fónicas que caracterizan siempre una estructura general $y$, a la vez, particular.

Como hemos dicho, cualquier texto literario destinado a ser traducido a otro idioma exige una suma de conocimientos teóricos y prácticos. En ese sentido sería conveniente recurrir a la noción concreta de estilo artístico. Pronto se nota que esa noción hace falta casi siempre, por su orientación objetivista y racional, en la teoría de la comunicación. Por tanto no es sorprendente que los fines mismos de la traducción artística nos llevan a la naturaleza específica y viva de una obra literaria. Está constituida por la esencia misma de la creación artística, por el funcionamiento de los tropos y las figuras que participan en cada acto creativo reforzando su función estética. Durante el aprendizaje de esos medios se puede ver cómo un escritor los emplea a cómo un traductor debería familiarizarse con ellos para traducir lo más fielmente su naturaleza original.

Para ilustrar ese proceso de familiarización propongo, no sin razón, a mis estudiantes un texto hispanoamericano. Su autor es Esteban Echeverría, el argentino, y pertenece al movimiento romántico que es el más fecundo en el siglo XIX hispanoamericano. Después de enumerar en las clases de historia literaria las características del romanticismo (popularismo, americanismo, 
FRANEK

actividad libre, nuevo sentido de la naturaleza, etcétera) suelo distribuir a los estudiantes un texto interesante. Forma parte del tomo de Rimas, en el cual Echeverría incluyó su poema La Cautiva.

Un manual de historia literaria nos dice que la obra representa su afán de americanizar la literatura y ofrece al lector una imagen fiel de la vida y de la naturaleza argentina. Los versos están llenos de fenómenos naturales al reflejar la intención del autor quién quiso pintar algunos rasgos de la fisionomía poética del desierto. Además nos enteramos también del argumento de la obra: narración poética de la huída del campamento indio y de un intento frustrado de los protagonistas de llegar a la civilización. El poema se inicia con los siguientes versos:

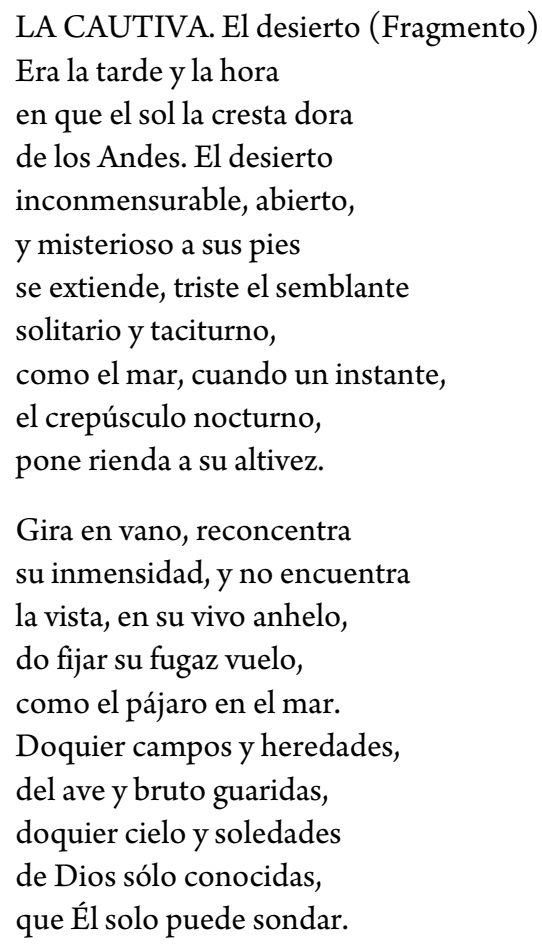

En cuanto al estilo poético, registramos en Echeverría utilización de recursos típicos del romanticismo: abundancia de metáforas que expresan rasgos poéticos de la naturaleza (el sol cresta dora, el desierto abierto, ...inconmensurable). El sintagma "triste el semblante" indica que el autor, impregnado por su visión grandiosa, se vale en la descripción de la prosopopeya o personi- 
ficación (el desierto es solitario y taciturno como el mar), es decir del tropo que llena todos los versos de la primera estrofa.

Los estudiantes tienen que preparar la traducción de ese fragmento en casa $y$, se puede decir, los versos citados no representan gran obstáculo para la interpretación semántica. A pesar del carácter metafórico y figurativo cada palabra encuentra un equivalente apropiado en el eslovaco (el único problema surge acaso con sintagmas "a sus pies"- pod nimi; o "pone rienda" - skrotí). Bien que se trata de un texto poético, no se exige su traducción total, con observación de todos los recursos versales hallándose en el original (construcción de rimas, de sus combinaciones o de su estructura fónica). La traducción eslovaca debe mostrar primero exactitud en la percepción semántica del original que es altisonante, enfático. Y como tal tiene rasgos marcados de oralidad popular reforzada en Echeverría por su capacidad de pintar la cara poética del desierto.

Sin embargo, la siguiente estrofa parece más difícil. ¿Dónde debemos buscar el sujeto de los primeros versos? Tardamos en descifrar que es la palabra "la vista", ya que el poeta argentino se sirve de ordinario del hipérbaton oscureciendo deliberadamente la lectura de sus poesía. Otro problema: las palabras "reconcentra su inmensidad" requieren una traducción libre (upiera sa na jeho mohutnost' príp. š́ravu). Fijémonos ahora en que las palabras do, doquier son anticuadas. Es obvio que no las encontraremos en los pequeños diccionarios, pero sí, en el gran diccionario de J. Dubský (1992) que es un material indispensable, precioso y suficientemente detallado para cada traducción, no solamente la artística. Luego vemos que las palabras "heredades" $y$ "soledades" que parecen difíciles de traducir, acaban por tener en nuestro idioma el equivalente preciso (usadlosti, horské samoty).

En resumen, si atendemos a la semántica del original la Cautiva de Echeverría posee una riquísima gama de recursos propiamente románticos: empleo de los tropos como prosopopeya, metáfora y comparación que determinan su modo de poetizar la naturaleza. Y que, como tal, esa grandilocuencia nos hace recordar la poesía de nuestros autores románticos (Ján Botto, Samo Chalupka y otros) donde aparece el semejante núcleo temático sobre la coexistencia del hombre y de la naturaleza. Así que la explicación y traducción del original nos permite pasar a una productiva comparación con el movimiento romántico en Eslovaquia que ha conocido en esa época, en el siglo XIX, el semejante florecimiento. En esta ocasión surge, naturalmente, una serie de preguntas. Por ejemplo: ¿hay una diferencia entre la divinización de la naturaleza de Echeverría y la de los poetas eslovacos de la época romántica? ¿Qué monte eslovaco se alza en la poesía de Andrej Sládkovič (Detvan) en vez de los Andes 
tan magníficamente descritos por el poeta argentino? ¿Se trata solo de una emancipación nacional declarada por la generación romántica que, como Andrés Bello, destacaba también las raíces profundamente americanas, todo lo que sobrepasaba las fronteras de un pueblo hispanoamericano? ¿Cuál es el concepto de héroe, el típico justiciero en ambas literaturas? ¿Son los protagonistas afines o bien qué anhelo les separa por causa de diferentes condiciones geográficas e históricas? Una misma comparación se nos brinda asimismo en relación con la poesía española; pienso sobre todo en el poema Himno al Sol de José Espronceda, que posee claramente otra tonalidad, más íntima, personal y más pesimista. En resumen, son las cuestiones que contienen, además de la explicación y el comentario de un texto hispanoamericano, la comparación cultural e histórica que separa y, a la vez, une dos realidades cercanas y distintas.

Después de dedicarse al tema y aspecto semántico de "La Cautiva" sigue el análisis formal del original, de su estructura rítmica. Un manual de métrica española (de José Domínguez Caparrós o de Antonio Quilis, por ejemplo) nos advierte que se trata del romance escrito en una serie de octosílabos (versos de arte menor), en la estrofa compuesta de diez versos (décima). Son los versos con rima consonante (con excepción de una combinación de rimas) en que la

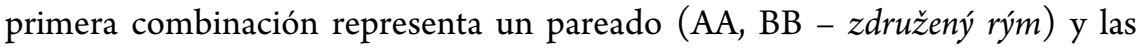
siguientes tienen un esquema obligatorio particular, con rima encadenada (striedavý rým), colocada en rima abrazada (ABCBCA - obkročný rým).

En cuanto a clases de rima que consideran tanto su timbre como su cantidad, los versos tienen casi todos la rima total o perfecta (en la terminología eslovaca bohatý o postačujúci rým). Se nota bien que el carácter fónico de rimas refleja dentro del verso metafórico de Echeverría también los recursos típicos de la poética romántica. Gracias a ello, el poeta argentino consiguió una ejemplar homogeneidad estilística en toda la estructura estrófica y versal.

En la segunda fase de análisis sobresale un fenómeno importante: es precisamente él en que consiste gran diferencia entre el verso español y el eslovaco. Se trata del acento métrico que tiene en ambas estructuras un carácter radicalmente distinto. En las clases de Estilística donde se analiza con mucha atención ese fenómeno, el estudiante tiene la ocasión de aprender que la acentuación española está determinada por normas gramaticales de pronunciación que son relativamente fijas. Por otro lado, la acentuación eslovaca se funda en la regla más o menos obligatoria sobre colocación del acento en la primera sílaba de las palabras. Su naturaleza fónica y morfológica exige que las cláusulas rítmicas o los pies métricos tengan actuación distinta en nuestro verso. A pesar de que la denominación y el número de acentos son iguales en ambos sistemas 
prosódicos. Según Andrés Bello quien es considerado el fundador de la métrica española (Principios de Ortología y Métrica, 1835), la naturaleza acústica del verso se destaca por su división en partes de duración fija. Son cinco: dos disílabas y tres trisílabas. Si el acento cae en la primera sílaba, hablamos de cláusula trocaica (óo), si en la segunda, recibimos cláusula yámbica (oó). Además hay tres cláusulas trisílabas: dactílica (óoo), anfibráquica (oóo) y anapéstica (ooó).

Una de las tareas de los estudiantes es inventar los ejemplos que prueben el carácter diferente de acentuación en ambos idiomas. De tal manera pueden comprobar que en nuestro idioma prevalecen absolutamente las cláusulas trocaicas, yámbicas y dactílicas (en vez de las anapésticas y anfibráquicas del verso español). Añadimos que el problema de acentuación es de gran importancia porque al tomar todos los componentes fónicos y sintácticos (existencia común de "pausas métricas y "cesuras") el acento representa el único rasgo verdaderamente distintivo por comparación de ambas métricas. Esta diferencia tiene como consecuencia, consecuencia realmente esencial, que la creación poética obedece a un específico ritmo interior que se percibe dentro de cada idioma. Se puede decir que en la poesía eslovaca el ritmo se debe mucho más a la regularidad acentual que resulta en algunas épocas (sobre todo en la versología yámbica de los poetas de la generación de Hviezdoslav) obligatoria dictada por una regla fija. Lo que demuestran asimismo muchas canciones populares eslovacas que frente al "flamenco español", por ejemplo, adquieren hasta una señal de recitación a coro. Es obvio que aquella regularidad métrica pueda parecer a un oyente español un tanto monótona. Pero normalmente es la que impulsa a nuestro traductor, casi en cada situación, a elegir una forma métrica particular y distinta. Puesto que el lenguaje eslovaco se somete a otras leyes rítmicas y melodiosas, típicas de su oralidad.

$\mathrm{Si}$ consideramos desde ese enfoque los versos del original, observamos primero clara regularidad en la acentuación de la penúltima sílaba („horadora"). Es interesante que para una percepción atenta podamos aplicar a ese análisis, y con mayor éxito, otro modelo de interpretación rítmica del verso español. Su autor es Rafael de Balbín quién, a diferencia de A. Bello, se propuso analizar la realización métrica del verso español a partir de la posición del acento al final. En su percepción importa la colocación del acento en relación con los anteriores en el interior del verso (Balbín mismo habla del signo par o impar que depende en su modelo únicamente del sistema disílabo: yámbico $\mathrm{y}$ trocaico, mientras que las cláusulas ternarias están suprimidas). Al detenerse en el lugar del acento en el interior de dados versos, vemos el acento en la 
FRANEK

primera o tercera o quinta sílaba (versos 2,3,4,6,7,8). El signo par aparece a su vez en otros versos $(1,5)$. Se trata pues, además de unos pocos "desvíos", del ritmo yámbico.

Al lado del acento métrico interior hay que tener en cuenta también clasificación de las palabras por la posición del acento. De ahí la división según su posición aguda, llana, esdrújula o sobresdrújula. En el texto citado encontraremos de acuerdo con esa clasificación, excepto el último ejemplo, la posición llana (acentuación de la penúltima sílaba). En cuanto a la métrica española es verdad que los estudiantes tienen buenos conocimientos adquiridos ya durante sus estudios secundarios. Lo cual facilita la explicación silábica del verso. Después de computar todas las sílabas descubrimos identidad silábica en toda la estrofa (el verso octosílabo). La posición aguda está presente una sola vez por lo cual somos obligados a disminuir el número real de sílabas en los versos rimados ( 8 en vez de 9) como lo prescribe la regla.

Otro rasgo distintivo de la métrica española, relacionado con el cómputo silábico, es el empleo frecuente de la sinalefa: aparece casi en todos los versos de Echeverría e influye en la identidad silábica para conseguir la deseada repetición periódica dentro de la estrofa.

Se puede decir que el acento métrico, su posición en las palabras y la división sintáctica son los elementos fundamentales en el aprendizaje de la métrica española. Al mismo tiempo, sirven de un contraste a la métrica eslovaca que posee, hemos visto, sus propias leyes de construcción. Es cierto que todos esos conocimientos complementan de modo orgánico los datos o las notas aprendidas anteriormente en el plano histórico, temático o estilístico.

Atención prestada al ritmo de un idioma coincide directamente con mis estudios analíticos, sincrónicos y diacrónicos donde el ritmo de la traducción poética es un medio ordenador de su estructura fónica y semántica. Al estudiar las traducciones eslovacas de Paul Claudel he comprobado que cada uno de los traductores eslovacos transponiendo la poesía de ese eminente neo-simbolista francés al eslovaco, se atenía a la regla dominante de versificación de su época. El metro que empleaban era sea yámbico, sea silábico ( acento) o dáctilo-trocaico. Es importante señalar que el metro elegido determinó asimismo la construcción semántica y sintáctica de dadas traducciones (Octavio Paz dice con razón que el sentido es el hijo del sonido). Y que las soluciones métricas en las traducciones poéticas de ese poeta han desembocado en las excelentes traducciones de Karol Strmeň, en una interpretación libre y fiel del claudeliano "verset bíblico“. 
Pues, para que la traducción alcance esa fidelidad es necesario percibir la estructura del verso en totalidad de sus componentes fónicos y semánticos. Y sobre todo saber que si se quiere apropiar en extensión y profundidad la poética del autor, su expresión tiene que reflejar ante todo el mundo irreemplazable de un artista, sus dones de imaginación y de creatividad individual. El ritmo es algo que no se puede captar, describir o identificar solo por vía estadística, hay que sentir y resentirlo por el compás mismo de la obra artística y de la traducción. Tal como lo sentía, por ejemplo, otro gran versólogo español Tomás Navarro Tomás quién fundó su concepto en las leyes de una composición musical. Gracias a su inteligencia y su erudición admirable ha sabido experimentar y registrar en una visión histórica variada gama de tonalidades y elementos fónicos de su propio idioma y del verso castellano (Métrica española, 1968).

Como hemos indicado, la enseñanza de la traducción literaria consta de varias fases del aprendizaje teórico y práctico. Con la ayuda de diccionarios, de manuales de historia literaria, de teoría de la comunicación, de estilística o de versología es posible construir poco a poco un edificio sólido cuyas partes, por el acto mismo de traducir, se entremezclan para hallar por fin el más duro cimiento. Sin embargo, una de las preguntas básicas es el lugar de la teoría literaria y de la literatura comparada en ese proceso. Refiriéndose a Claudio Guillén, el comparatista español, existe una gran diferencia entre esas dos disciplinas aunque, por ejemplo, en el sistema educativo de las universidades españolas ésas aparecen actualmente como títulos duales. A su modo de ver se trata de disciplinas distintas que "para ser practicadas requieren, en el caso de una o de la otra, una preparación intensa, muy particular y adecuada" (Guillén 2005: 15). Parece absolutamente normal que desde un punto de vista eslovaco no sería posible pronunciar las mínimas objeciones o apoyos sólidos a su opinión, en cuanto a un "desconcierto" que caracteriza la práctica conjunta de esas dos disciplinas en algunas universidades españolas. Es verdad que la riquísima herencia del comparatismo de Dionýz Ďurišin de la "Escuela de Bratislava", como pretende un poco erróneamente en uno de sus estudios el Profesor César Domínguez de la Universidad de Santiago de Compostela, es actualmente en Eslovaquia casi absolutamente desconocida, o bien, para corregirlo, se presta atención casi exclusivamente al desarrollo posterior de esta disciplina cultivada por el científico eslovaco bajo el título de Teoría

\footnotetext{
1 /... / los estudios de Ďurišin y otros miembros de la Escuela de Bratislava son prácticamente desconocidos. In: DOMÍNGUEZ, C.: La Literatura Comparada y la Teoría Interliteraria en/desde España, p. 10 (Porovnávacia literatúra a teória medziliterárnosti v Španielsku / z pohladu Španielska. Slovak Review, 2009; v tlači).
} 
FRANEK

Interliteraria. Digámonos que ésa se dirige, sobre una plataforma más amplia, generalista y globalista, al estudio de las comunidades interliterarias, europeas y mundiales. Es obvio que en la segunda fase Ďurišin ha tenido que abandonar muchos de sus conceptos básicos, desarrollados y dilucidados, por ejemplo, en el libro La Teoría del comparatismo literario (1975). ¿No es esa razón que, unida a otras razones, políticas e ideológicas, ha originado una inexistencia del área de literatura comparada en las universidades eslovacas aunque la nueva apertura democrática y el nuevo europeísmo, al parecer, lo exigían? ¿No se puede tener por gran lástima que una suma preciosa de conocimientos teóricos de Ďurišin se haya perdido para nuevas generaciones de estudiantes eslovacos quienes hubieran podido aprovechar y profundizar, también por su propia experiencia "más abierta", su pensamiento valioso?

Afortunadamente, lo que sigue en pie, es cierto grado de comparatismo presente en el área de traducción literaria que se incluye de un modo integrante y seguramente curioso en el de traductología, nacida hace pocos años, en los años noventa del siglo XX. Sobre todo bajo los impulsos del Gabinete de la Comunicación Literaria en Nitra cuyos principales modelos teóricos permanecen en sus líneas generales desde la época comparatista de Ďurišin, ha podido salvarse al menos una parte de la tradición específica eslovaca bien que, por otro lado, ese campo no podía aprovechar de modo suficiente toda la extensión teórica de nuestro comparatismo. El objetivo de mi contribución es rehabilitar y enriquecer esa herencia, válida asimismo para fines pedagógicos.

Estoy convencido de que el método complejo y complementario que caracteriza la enseñanza de la traducción literaria en algunas universidades eslovacas representa un instrumento precioso para que se pueda pasar de la relación habitual autor/traductor, obra original/traducción a las esferas más amplias acerca del funcionamiento y lugar de las literaturas nacionales. Sobre todo en el caso de que éstas sean observadas dentro y fuera de sus propias coordenadas temporales y espaciales. Hay que repetir que desde ese enfoque resulta muy productiva la conjunción de tres asignaturas: la tradicional Historia de la Literatura (en nuestro caso la Española y la Hispanoamericana) con la Estilística Literaria (dedicada por ejemplo al dominio "supranacional" del funcionamiento de los tropos y figuras así como a otro "problema poético y general" que toma en consideración las diferencias prosódicas entre ambos idiomas). La tercera asignatura está constituída por el área de Traducción misma, con variedad de cuestiones teóricas y prácticas planteadas siempre con respecto al fenómeno enseñado: poética individual del autor, manera de 
traducir su texto a partir de los rasgos peculiares, poetológicos, estilísticos y lingüísticos.

Desde luego, en ese examen halla aplicación el método comparativo que debería aprovechar los conocimientos de Historia y Teoría de la Literatura, junto con necesidad de tomar una posición crítica. Para ello es indispensable a cada momento darse cuenta de un problema. El profesor de Traducción Literaria, siendo algunas veces traductor, crítico e investigador, tiene que situarse en una actitud particular, dinámica y dialéctica. No puede identificarse exclusivamente con el científico ni con el filósofo como si se encontrara en el cruce de varios impulsos, muchas veces imprevisibles, abiertos a la búsqueda de nuevas relaciones y correspondencias. El objeto de estudio es aquél que le determina también su percepción momentánea que puede cambiar de un momento a otro bajo la presión de nuevos estímulos, asociaciones o sugerencias. En ese sentido el enfoque histórico le permite considerar las dimensiones espaciales y temporales, sincrónicas y diacrónicas. En resumidas cuentas, se trata de un método dinámico que observa tanto la diferencia individual como la perspectiva unitaria. Lo más importante, como subraya varias veces Claudio Guillén, es eliminar cada perspectiva unilateral, postulada a priori. De tal suerte la historia y crítica literaria van unidas, tienen su propio carácter complementario sin omitir su papel específico.

Después de esas reflexiones básicas hay que preguntarse: ¿qué papel desempeña desde esa óptica totalizadora en que la traducción literaria se liga a la literatura comparada, la teoría literaria? ¿No es acaso el problema clave que condiciona el contenido mismo de esas disciplinas, su funcionamiento relativamente independiente? ¿Podría la teoría literaria corresponder precisamente a lo que quisiera postular la literatura comparada? ¿Qué rasgos comunes tienen ambas disciplinas en la investigación de las relaciones supranacionales.

Con el fin de contestar, al menos parcialmente, a esa pregunta voy a salir de mis propias experiencias durante el estudio comparativo que he aplicado en gran medida en el libro titulado El Estilo de la traducción (Análisis evolutivo, teórico y crítico de las traducciones eslovacas de Paul Claudel (VEDA 1997). La fecha de la edición de ese libro no dice nada, por cierto, de sus destinos difíciles y forzosamente interrumpidos porque mi estudio comparativo se desenvolvía ya desde comienzos de los años setenta del siglo XX. Poco se sabe de que esa época estaba marcada por una verdadera "bulla teórica" que se centraba en el Instituto de Literatura Mundial y Lenguas de la Academia Eslovaca de Ciencias en Bratislava. Por una parte, en ese establecimiento proseguían investigaciones en el ámbito de Poética Histórica, bajo la dirección del Director del Instituto 
FRANEK

Mikuláš Bakoš, por otra parte, aquellos años conocían en el mismo lugar un desenvolvimiento fértil y sumamente internacional de teoría del comparatismo literario (Dionýz Ďurišin); a lo que se sumaban esfuerzos de sistematización dentro de una disciplina nueva, la teoría de comunicación. Siendo patrocinada por el teórico de traducción literaria Anton Popovič, ésta fue cultivada primordialmente en el Gabinete de Comunicación Literaria en Nitra. En ese contexto no se puede olvidar tampoco el papel importante que está jugando en nuestro país la crítica de traducción en que se reúnen desde hace mucho varios conceptos o accesos eslovacos (Jozef Felix, Blahoslav Hečko y otros) y checos (Jiří Levý).

Por ejemplo, una actuación estimulante de la reflexión crítica de Jozef Felix, el único traductor, hasta hoy día, de Don Quijote al eslovaco, residía en el horizonte inmenso que abarcaba, con un ahondado saber, también la modernidad de las literaturas europeas, ante todo la francesa. Es sobre esa base, con un afán crítico e iluminador que él procedía a algunas traducciones eslovacas para demostrar errores de interpretación, una ignorancia total o parcial del original, una preparación insuficiente antes del acto mismo de traducir. Ese interés no era único: sus juicios y observaciones severas atañían a la necesidad de "abrirse al mundo", de liberarse de los cauces estrechos y aislados de la literatura eslovaca. Todo esto tenía como finalidad un anhelo importante: el de insistir en la autonomía de la literatura frente a cualquier imperativo prevaleciente que consideraba la función de la literatura nacional como fuente determinante de su desarrollo. Es cierto que Felix hizo el primer paso al revalorizar estudios históricos y críticos de las literaturas románicas, para entrar en las áreas más amplias del conocimiento trans-histórico y supranacional. Acaso no debo añadir qué influencia, tras tantos años de olvido y silencio, tiene su espíritu analítico para la actualidad, hasta qué punto sus estímulos son de gran valía en función de una rehabilitación necesaria de la literatura como objeto esencial de la literatura comparada y de la traducción.

Es bueno que esa actividad pluridimensional resulte hoy día, creamos, liberada de desagradables presiones y represiones ideológicas del pasado. Se basa en una valoración y revisión crítica, en una discusión libre y equivalente entre el profesor (actuando solo como un guía del común diálogo constructivo) y sus alumnos, en la modestia misma de los procedimientos abiertos, caracterizadores y reveladores (¿en qué espacio la gente puede, de la misma manera, corregir y autocorregirse?). A través de la traducción penetramos en diferentes mundos para franquear con más ligereza los límites que separan y siguen separando las naciones. Al sentir acaso que no podamos 
ser grandes idealistas. Pero que por las traducciones, por el diálogo cultural no olvidaremos el sentido mismo de la creación artística cuya misión primordial es desde siempre una defensa. ¿No es ése el ideal que nos había proporcionado la generación romántica, hispana y eslovaca? La defensa ante todo el peligro que nos acecha y que puede mejor expresar la literatura.

Al seguir sus sendas, difíciles en cada época, encontraríamos con más claridad nuestro lugar en un cruce de culturas a fin de perpetuar, por medio de creación y recreación, su imagen viva y sensible en el porvenir.

\section{Bibliografía}

Bakoš, M. 1966. Vývin slovenského verša od školy Štúrovej (Evolución del verso eslovaco desde la Escuela de Štúr). Bratislava: VSAV.

Caparrós Domínguez, J. 1993. Métrica española. Madrid: Ed. Síntesis.

Cohen, J. 1970. Structure du langage poétique. Paris: Flammarion.

Dubský, J. 1992. Španělsko-český slovník (Diccionario Español-Checo). 5. vyd. Praha: SPN.

Ďurišin, D. 1975. Teória literárnej komparatistiky (Teoría del comparatismo literario). Bratislava: Slovenský spisovatel.'

Guillén, C. 2005. Entre lo uno y lo diverso. La Literatura Comparada (Ayer y hoy). Barcelona: Ed. Marginales Tusquets.

FRANCO, J. 1982. Historia de la literatura hispanoamericana. Barcelona: Ariel, 476 p.

FRANEK, L. 1997. Śtýl prekladu. Vývinovo-teoretická a kritická analýza slovenských prekladov Paula Claudela (Estilo de la traducción. Análisis evolutivo-teórico y crítico de las traducciones eslovacas de Paul Claudel). Bratislava: VEDA.

Lázaro Carreter, F., Correa Calderón, E. 1974. Cómo se comenta un texto literario. Madrid: Cátedra.

Navarro Tomás, T. 1968. Métrica española. Reseña histórica y descriptiva. La Habana: Instituto del Libro.

Paz, O. 1983. Sombras de obras. Barcelona: Biblioteca de bolsillo.

Popovič, A. 1968. Preklad a výraz (Traducción y expresión). Bratislava: SAV.

Quilis, A. 1994. Métrica española. Barcelona: Ed. Ariel. 